\title{
Reduction of the Zöllner illusion with motion of inducing figure
}

\author{
TERUNORI MORI \\ Electrotechnical Laboratory, 1-1-4 Umezono, Sakura-mura, Niihari-gun, Ibaraki-ken, Japan 305
}

\begin{abstract}
The magnitude of the Zöllner illusion was measured when the inducing lines moved rightward or leftward and were tracked by subjects. Motion of the inducing lines significantly reduced the magnitude of illusion, as in the Poggendorff illusion. Increasing velocity markedly increased the reduction, and, again, this effect was not significantly different from that obtained with the Poggendorff illusion. The current evidence seems to support the suggestion outlined earlier in relation to the Poggendorff illusion, that is, moving and stationary figures are processed by separate channels and, therefore, the interaction between them is reduced.
\end{abstract}

An earlier paper (Mori, 1981) reported that, when a subject tracked the moving parts of the figure, the Poggendorff effect was significantly reduced when the oblique lines were in motion and the parallels were stationary. This suggested a reduction of the interaction between the test and inducing figures.

The question addressed in the present study was whether or not a significant reduction of illusion magnitude also would occur in the Zöllner illusion when some parts of the figure were in motion and other parts were stationary. Further, assuming that significant reduction did occur, how would the illusion magnitude change with velocity? Would reduction occur as a function of velocity as with the Poggendorff illusion?

The present experiments were designed to answer these questions. Illusion magnitude was measured under conditions in which the inducing figure was moved horizontally while being tracked by a subject. The horizontal parallels remained stationary.

\section{EXPERIMENT 1}

\section{Method}

Apparatus. A Megraphic 5000 display monitor (P31 phosphor), controlled by a NOVA-3 minicomputer, was used. The display was viewed in a darkened room. The subject was seated $50 \mathrm{~cm}$ from a screen, with head upright and chin in a chinrest.

Figure 1 shows the stimuli used in the experiments. Horizontal lines $A B$ and $C D$ were $4.5 \mathrm{~cm}(5.1 \mathrm{deg})$ in length. The vertical gap between horizontal parallels was $.75 \mathrm{~cm}(.9 \mathrm{deg})$ in Figure la and $1.13 \mathrm{~cm}(1.4 \mathrm{deg})$ in Figure $1 \mathrm{~b} .{ }^{1}$ The gap between the lower oblique lines and the upper oblique lines in Figure $1 \mathrm{~b}$ was $.38 \mathrm{~cm}(.5 \mathrm{deg})$. The angle between the obliques and parallels was 45 deg in Figure la and $30 \mathrm{deg}$ in Figure $1 \mathrm{~b}$. The oblique lines emerged from one side of a window, of which the diameter was $7 \mathrm{~cm}(8.0 \mathrm{deg})$, and moved to the opposite side. All lines had a luminance of $1 \mathrm{~mL}$. The luminance of the background screen was not measurable using a Tektronix J 16 digital photometer, but was less than $.01 \mathrm{~mL}$, the lower limit of the photometer. Thus, contrast, defined as $\left(\mathrm{L}_{\max }-\mathrm{L}_{\min }\right) /\left(\mathrm{L}_{\max }+\mathrm{L}_{\min }\right)$, exceeded .98 .

Procedure. Each subject completed four conditions: a control, in which the oblique lines were stationary, a pretest in which only test lines $\mathrm{AB}$ and $\mathrm{CD}$ were displayed, and two experimental conditions in which oblique lines were moved left or right with the subject tracking them at a rate of $1.7 \mathrm{deg}$ of visual angle per second. The order of the four conditions was changed randomly. On each trial, the observer judged whether $B D$ was smaller than $\mathrm{AC}$ or $\mathrm{AC}$ smaller than $\mathrm{BD}$. The position of point $\mathrm{C}$ was changed after each trial. Thus, a subjective error of parallelism was measured using a double, randomly interleaved staircase technique (e.g., Cornsweet, 1962; Wetherrill \& Levitt, 1965).

Subjects. Seven volunteers were used. Five of them were tested with the stimulus of Figure la, and the other two were tested with the stimulus of Figure 1b. All had normal or corrected vision.

\section{Results}

The results of experiments are shown in Tables 1 and 2. Each value in Tables 1 and 2 was calculated from simple means of errors in the two experimental conditions. These results show that the Zöllner illusion was significantly reduced when the oblique lines moved horizontally and the subject's eyes tracked them, as was the case with the Poggendorff illusion.

The reduction magnitude with Figure $1 \mathrm{a}$ was about $58 \%$ and with Figure $1 \mathrm{~b}$ about $50 \%$.

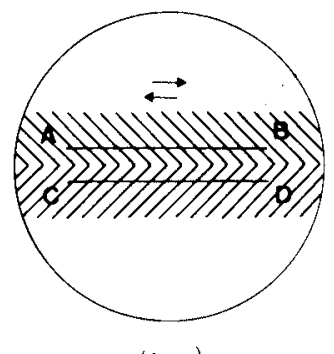

$(\mathbf{1}-\mathbf{a})$

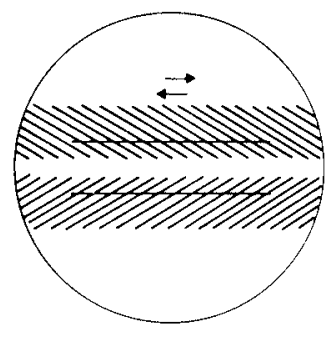

$(\mathbf{1}-\mathbf{b})$
Figure 1. Stimuli used in the experiments. The screen was $35.6 \mathrm{~cm}$ wide and $33.0 \mathrm{~cm}$ high and included a $7-\mathrm{cm}$-diam window. The horizontal separation between oblique lines was $.37 \mathrm{~cm}$. The oblique lines were $1.13 \mathrm{~cm}$ high. The angle between the obliques and parallels was 45 deg in Figure $1 \mathrm{a}$ and $30 \mathrm{deg}$ in Figure 1b. 
Table 1

Reduction in Illusion Magnitude With Motion of Inducing Lines Using Figure 1a

\begin{tabular}{|c|c|c|c|c|c|c|}
\hline \multirow[b]{3}{*}{ Subject } & \multicolumn{4}{|c|}{ Illusion Magnitude (in Millimeters } & \multirow[b]{3}{*}{$t(8)$} & \multirow[b]{3}{*}{$\mathrm{p}<$} \\
\hline & \multicolumn{2}{|c|}{ Stationary } & \multicolumn{2}{|c|}{ Moving* } & & \\
\hline & Mean & SD & Mean & SD & & \\
\hline K.M. & .51 & .15 & .07 & .10 & 4.79 & .05 \\
\hline Y.M. & .55 & .13 & .28 & .09 & 3.42 & .01 \\
\hline S.S. & .55 & .11 & .35 & .14 & 2.29 & .08 \\
\hline K.T. & .78 & .10 & .33 & .07 & 7.49 & .001 \\
\hline Y.T. & .58 & .10 & .17 & .14 & 4.90 & .005 \\
\hline Mean & .59 & .10 & .24 & .11 & 4.71 & .005 \\
\hline
\end{tabular}

Note-The reduction was $58 \%$ at a rate of $1.7 \mathrm{deg} / \mathrm{sec}$. *1. $7 \mathrm{deg} / \mathrm{sec}$.

Table 2

Reduction in Illusion Magnitude With Motion of Inducing Lines Using Figure 1b

\begin{tabular}{ccccccc}
\hline \multicolumn{6}{c}{ Illusion Magnitude (in Millimeters) } \\
\cline { 2 - 5 } Subject & \multicolumn{2}{c}{ Stationary } & \multicolumn{2}{c}{ Moving* } \\
\cline { 2 - 4 } & Mean & SD & Mean & SD & t(8) & $\mathrm{p}<$ \\
\hline N.I. & .95 & .08 & .52 & .14 & 5.44 & .01 \\
S.F. & 1.29 & .22 & .66 & .16 & 4.67 & .005 \\
\hline
\end{tabular}

Note-The reduction was about $47 \%$ at a rate of $1.7 \mathrm{deg} / \mathrm{sec}$. *1. $7 \mathrm{deg} / \mathrm{sec}$.

\section{EXPERIMENT 2}

This experiment was planned to see how the adjustment error of the Zöllner illusion changes with the velocity of the oblique inducing lines.

\section{Method}

In the case of the Poggendorff illusion, the reduction in magnitude at $2.7 \mathrm{deg} / \mathrm{sec}$ was $80 \%$ of that at $21.2 \mathrm{deg} / \mathrm{sec}$. Therefore, the adjustment errors here were measured at four low velocities: $0, .7,2.0$, and $3.4 \mathrm{deg} / \mathrm{sec}$.

The subjects completed five conditions: a control in which the inducing lines were stationary, a bias in which the inducing lines were deleted, and three experimental conditions in which the inducing lines moved at one of three velocities. The order of the five conditions was determined randomly. Two subjects were tested with Figure la and the other two with Figure $1 \mathrm{~b}$.

\section{Results}

The changes of the adjustment error with Figure 1a are shown in Figure 2a. A significant reduction of illusion magnitude was not observed at the low velocity of $.7 \mathrm{deg}$ of visual angle per second $[\mathrm{t}(8)=$ $2.23, \mathrm{p}>.05 ; \mathrm{t}(8)=1.40, \mathrm{p}>.10]$, but a significant reduction of illusion magnitude was observed for both subjects at the velocity of $2.0 \mathrm{deg}$ of visual angle per second $[\mathrm{t}(8)=3.11, \mathrm{p}<.05 ; \mathrm{t}(8)=3.02, \mathrm{p}<.05]$.

The changes with Figure $1 \mathrm{~b}$ are shown in Figure $2 \mathrm{~b}$. A significant reduction of illusion magnitude was observed at all of the velocities tested.

The reduction as a function of velocity was very steep and was similar to those obtained with the Poggendorff illusion. One of the reasons for not testing at higher velocities was a limitation of the apparatus. Another was that tracking the Zöllner inducing figure was difficult at the high velocity.

\section{DISCUSSION}

In the current experiments, reduction in the magnitude of the Zöllner illusion was measured under conditions in which the inducing figure moved horizontally as subjects tracked it. The aim was to investigate whether or not a significant reduction of the illusion magnitude was observed, as occurred in the Poggendorff illusion, and to compare the velocity functions for the two illusions. One of 11 subjects (S.S.) showed some reduction in illusion magnitude at a rate of $1.7 \mathrm{deg} / \mathrm{sec}$, but it was not significant (see Table 1). All other subjects, however, showed a significant reduction at this rate or at a higher velocity.

The reductions in the Zollner illusion were larger than those in the Poggendorff illusion. This difference may be related to a finding that, even in "without parallels" in the Poggendorff illusion, an align-

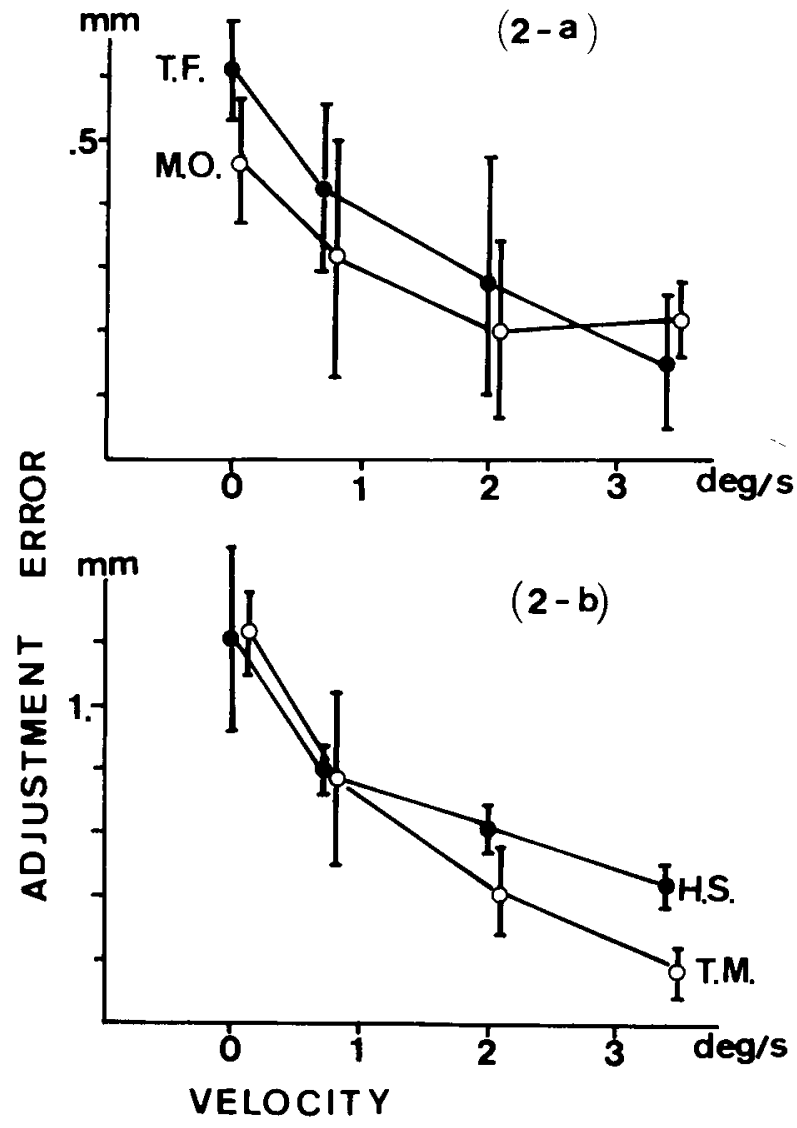

Figure 2. Changes of illusion magnitude with velocity. Figures $2 a$ and $2 b$ are the results obtained with Figures $1 a$ and $1 b$, respectively. Vertical bars represent standard deviations. 
Table 3

Zöllner Illusion With Whole Object Motion Using Figure 1b

\begin{tabular}{|c|c|c|c|c|c|c|c|c|c|c|}
\hline \multirow[b]{2}{*}{ Subject } & \multicolumn{2}{|c|}{ Stationary } & \multicolumn{4}{|c|}{ Moving 1} & \multicolumn{4}{|c|}{ Moving 2} \\
\hline & Mean & SD & Mean & SD & $t(8)$ & $\mathrm{p}>$ & Mean & SD & $t(8)$ & $p>$ \\
\hline T.M. & 1.23 & .21 & 1.29 & .12 & .496 & .5 & 1.33 & .34 & .500 & .5 \\
\hline K.T. & 1.16 & .19 & 1.04 & .08 & 1.16 & .1 & 1.07 & .14 & .594 & .5 \\
\hline H.M. & 1.12 & .21 & 1.08 & .19 & .282 & .7 & 1.04 & .16 & .606 & .5 \\
\hline
\end{tabular}

Note-Stimuli moved rightward at a rate of 3.4 deg of visual angle per second as a whole object. Subjects' eyes tracked the stimuli with Moving 1, but they stared at a stationary point with Moving 2.

ment error of about $32 \%$ of the "with parallels" effect was observed for the 45-deg orientation (Day, 1973). In the current experiments, a mean of adjustment errors of 11 subjects in "without inducing lines" was $.06 \pm 0.12 \mathrm{~mm}$. This was not significantly larger than zero $[t(10)=1.73, p>.1]$, but in the current experiments each illusion magnitude was corrected by subtracting an adjustment error in "without inducing lines" in order to reduce an individual difference. Therefore, the reductions as a function of velocity should be compared using this corrected illusion magnitude. In the Poggendorff illusion, the corrected reductions at the rates of 2.7 and $5.3 \mathrm{deg} /$ sec, $P_{2.7}$ and $P_{5.3}$, were $70.6 \% \pm 23.5 \%$ and $72.0 \%$ $\pm 29.4 \%$, respectively. In the Zöllner illusion, the corrected reductions at a rate of $3.4 \mathrm{deg} / \mathrm{sec}, \mathrm{z}_{\mathrm{a}}$ and $\mathrm{z}_{\mathrm{b}}$, were $63.0 \% \pm 24.1 \%$ for Figure $1 \mathrm{a}$ and $75.4 \pm$ $14.8 \%$ for Figure $1 \mathrm{~b}$. These were not significantly different from $\mathrm{P}_{2.7}$ and $\mathrm{P}_{5.3}$ [e.g., $\mathrm{t}(8)=.474, \mathrm{p}<.5$ between $P_{2.7}$ and $z_{a}$ ].

Provided that, at a rate of $2.0 \mathrm{deg} / \mathrm{sec}$ in the Poggendorff illusion, the reduction is given a simple mean of the reductions at rates of 1.3 and $2.7 \mathrm{deg} / \mathrm{sec}(61 \% \pm$ $16 \%$, it is not significantly different from those at the rate in the Zöllner illusion $[\mathrm{t}(18)=.825, \mathrm{p}>.3$ for Figure $1 \mathrm{a} ; \mathrm{t}(18)=.540, \mathrm{p}>.5$ for Figure $1 \mathrm{~b}]$. Together, these data for reduction as a function of velocity in the current experiments seem comparable to the data for the Poggendorff illusion. The results in the current experiments support one possibility described in Mori (1981), that is, that the figure in motion and the stationary figure may be processed by separate channels, thus reducing any interaction between the test figure and inducing figures.

Tracking of the inducing figure was introduced to avoid any blurring of the inducing figure and to keep both test and inducing figures as clear as possible, as in the earlier paper (Mori, 1981). Stationary line segments whose orientation is parallel with the direction of rapid eye movement are observed clearly, but we almost cannot see stationary line segments whose orientation makes a right angle with the direction of rapid eye movement. Therefore, an experimental condition in which a whole figure rapidly moves and the subject's eyes are stationary, or vice versa, loses its meaning in the current experiments because it looks like "without inducing lines." However, at a low velocity, the current reduction in illusion magnitude could be due to motion on the retina. Eye movement itself also could be a main cause of the reduction of illusion magnitude because it might inhibit any interaction between test and inducing lines or strengthen a parallelism between test lines.

Two control conditions were introduced to answer the above questions. In these tests, the subject either visually tracked a whole, moving stimulus or stared at a stationary point. The results, shown in Table 3 , indicate that eye movement itself or motion on the retina was not a main cause for the reductions of illusion magnitude. The results seem to show that the difference in velocity between test and inducing figures is important.

\section{REFERENCES}

Cornsweet, T. N. The staircase method in psychophysics. American Journal of Psychology, 1962, 75, 485-491.

DAY, R. H. The oblique line illusion: The Poggendorff effect without parallels. Quarterly Journal of Experimental Psychology, 1973, 25, 535-541.

Mori, T. Reduction of the Poggendorff effect by the motion of oblique lines. Perception \& Psychophysics, 1981, 29, 15-20.

Wetherill, G. B., \& LevitT, H. Sequential estimation of points on psychometric function. British Journal of Mathematical Statistical Psychology, 1965, 18, 1-10.

\section{NOTE}

1. The stimulus of Figure $1 \mathrm{~b}$ was introduced to test further for a reduction of the Zöllner illusion in order to confirm the results with respect to Figure la under different conditions.

(Manuscript received September 2, 1981; revision accepted for publication December 3,1981 .) 